\title{
Online or Blended Learning: the COVID-19 Pandemic and First-Year Medical Students' Academic Motivation
}

\author{
Aidos K. Bolatov ${ }^{1,2}$ - Anar M. Gabbasova ${ }^{1} \cdot$ Raushan K. Baikanova $^{1} \cdot$ Bahyt B. Igenbayeva $^{1} \cdot$ Dainius Pavalkis $^{3}$
}

Accepted: 4 November 2021 / Published online: 12 November 2021

(c) The Author(s) under exclusive licence to International Association of Medical Science Educators 2021

\begin{abstract}
The study aimed to investigate the influence of psychological well-being and different study format on the academic motivation of 1st-year medical students during the COVID-19 pandemic. Repeated cross-sectional study carried out in November 2020 (time 1) and March 2021 (time 2). During time $1(N=273)$, all students studied online. In time $2(N=159)$, both students who learned online only $(N=86)$ and students who were taking $(N=33)$ or passed offline classes $(N=40)$ were trained. The mental state of the students was stable overtime of observation. The effect of the level of psychological destruction and quality of life affecting by the COVID-19 pandemic on academic motivation was minimal. The level of academic motivation was higher in time 2; this was especially noticeable among students who underwent blended learning. The mediating role of satisfaction with academic life and college belongingness in the relationship between the learning format and motivation was found. Blended type of education during a pandemic is more favorable for students in terms of their motivation to study. Further epidemiological studies are needed to assess the safety of blended learning. However, we would like to emphasize that no cases of COVID-19 in the blended learning format have been reported.
\end{abstract}

Keywords COVID-19 $\cdot$ Academic motivation $\cdot$ Medical education $\cdot$ Medical students $\cdot$ Online learning $\cdot$ Blended learning

\section{Introduction}

The choice of medical studies depends on various factors. Goel et al. identified three domains: scientific, societal, and humanitarian [1]. Gąsiorowski et al. (2015) concluded that altruistic and scientific reasons are the main motives for choosing a medical career [2]. Narayanasamy et al. extracted the following factors that influence students to join medicine: personal growth, professional calling, personal concerns, and professional concerns factor [3]. However, the COVID-19 pandemic has resulted in significant burdens globally, and healthcare workers are at the epicenter of an unprecedented COVID-19 crisis [4]. Awareness of the role

Aidos K. Bolatov

bolatovaidos@gmail.com

1 Astana Medical University, Beybitshilik St. 49A, Z10K9D9 Nur-Sultan, Kazakhstan

2 National Research Center for Maternal and Child Health, CF "University Medical Center", Kerey-Zhanibek Handar St. 5/1, Z05P3Y4 Nur-Sultan, Kazakhstan

3 Lithuanian University of Health Sciences, A. Mickeviciaus str. 9, 44307 Kaunas, Lithuania of the profession, both in a personal and in a global concept, influenced the self-identification among 2020 entrants and future doctors. Crises such as the pandemic can change, hinder, or accelerate the medical students' professional identity formation [5]. An analysis conducted among first-year medical students in the USA showed that one third of students were concerned about their academic/professional futures [6]. It is also known that intrinsic and extrinsic motivation positively correlates with professional identity [7]. Findyartini et al. indicated that professional identity formation may change due to the COVID-19 pandemic [8]. Chandratre also points out the increasing barriers in professional identity formation among medical students [9].

After entering the university, the further education of students depends on the motivation to study. According to the social-cognitive approach, academic motivation is an interaction between a student's perceptions of his learning environment, learning behavior, and environmental factors [10]. Orsini et al. based on self-determination theory categorized the following determinants influencing motivation: intrapersonal such as gender and personality traits and interpersonal determinants such as academic conditions, lifestyle, and learning climate [11]. However, the abrupt transition to 
distance learning has had an ambiguous impact on medical education. Reducing face-to-face training could have contributed to a decrease in motivation and well-being. A significant number of students indicated that their motivation was influenced by distractions during the pandemic [12]. It has also been found that without academic input, students are more likely to be poorly motivated [13]. And as noted by Rahm et al. staying motivated to learn in social isolation during a pandemic can be challenging [14].

Moreover, the COVID-19 pandemic has disrupted the lives of many people across the world, including medical students [15]. Researches highlighted the negative impact of the COVID-19 pandemic on the psychological well-being of college students, who are likely to develop post-traumatic stress disorder, anxiety, depression, and other symptoms of distress [16]. A study conducted among students of a pedagogical university showed that there is a positive correlation between the perception of psychological well-being of participants and their academic motivation [17].

Given that motivation to study is a critical factor in determining learning outcomes [18], examining changes in student motivation during a pandemic in different learning environments will enable education policymakers to make recommendations for improving learning. Given the above, two central questions of this study were asked: (1) given the negative impact of the pandemic on the well-being of students and the uncertain impact on learning efficiency are the changes caused by the COVID-19 pandemic predicted academic motivation, and (2) how different forms of education affected the level of motivation in a pandemic? The study aimed to investigate 1st-year medical students' psychological well-being during the COVID-19 pandemic, education format, and its influence on academic motivation.

\section{Materials and Methods}

\section{Study Design and Participants}

This repeated cross-sectional questionnaire-based study was carried out from November 16 to 19, 2020 (time 1) and from March 18 to 25, 2021 (time 2) (Fig. 1). The study was attended by 1st-year medical students at Astana Medical University (Nur-Sultan city, Kazakhstan). In the 2020-2021 academic year, 586 students studied in the 1st year. During time 1, all students studied online only, 273 (46,6\%) of them participated in the current study. In online training, students were trained using web-based technologies without face-toface classes. Starting from February 15, 1st-year students began a blended type of study, combining online and offline classes (only Anatomy, Histology, and Physiology). During
Total number

of the 1st year medical students

in the 2020-2021 academic year: $\mathbf{5 8 6}$

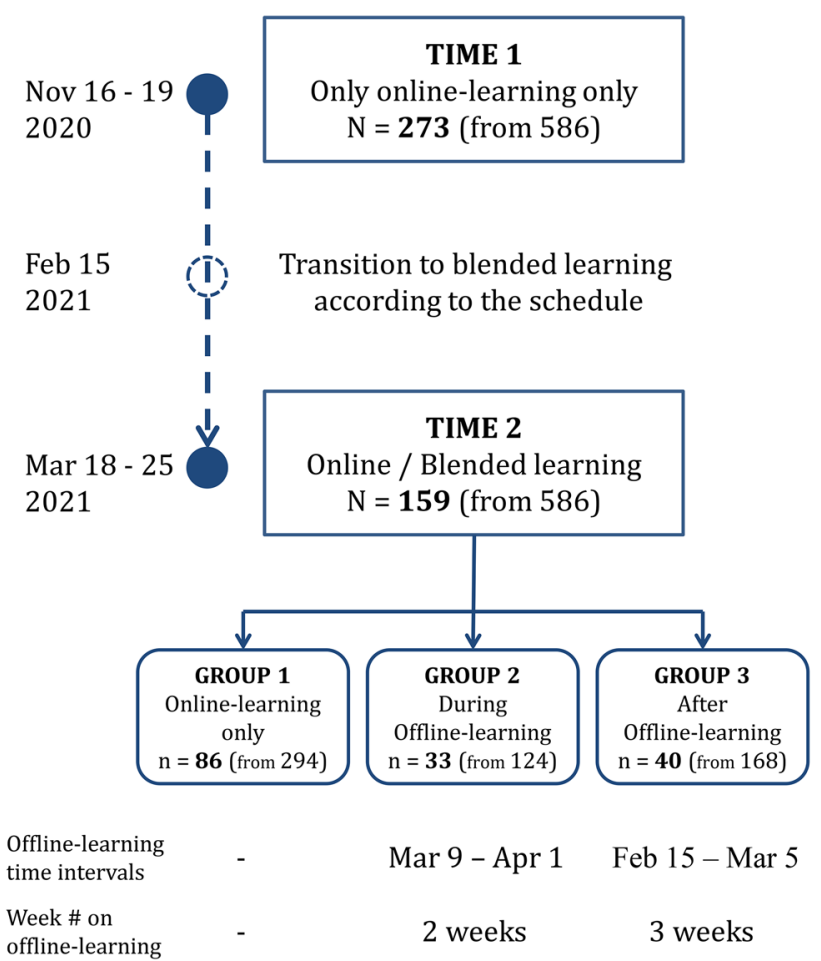

Fig. 1 Study design

periods of offline study, students attended traditional classes at the university. Offline classes included daily 2 -h practical sessions for 3 weeks. To ensure the sanitary and epidemiological regime during a pandemic, students went offline learning gradually, and then returning to online learning. Thus, during time 2 , both students who had not yet entered the blended type of education and students who were taking or passed offline classes were trained. In time 2, 168 students have already completed the offline training component from February 15 to March 5, 49 (29.2\%) of which took part in the survey, in the article they are designated as group 3. One hundred twenty-four students at the time of repeated study took offline courses (from March 9 to 1 April 2021), of which 33 (26.6\%) took part in the survey (group 2). At the time of the study, students from group 2 in time 2 had completed 2 of 3 weeks of offline courses. The rest of the students (294) have so far studied only online, 86 (29.3\%) of them participated in the study (group 1). Groups of students in time 2 were defined only according to the blended learning schedule set up by the Faculty of Medicine, and only consent to participate in this study was a criterion for inclusion. 


\section{Study Materials}

Quality of Life affecting by the COVID-19 pandemic was assessed by the 6-item COV19-QoL scale created by Repišti et al. [19]. The level of destruction that COVID-19 has created on the psychology of individuals was assessed by the COVID-19 Psychological Destruction Scale (COV-PDS) with "Collapse" and "Fear" dimensions created by Akan [20]. Mental health continuum of participants was assessed using the MHC-SF [21].

Academic motivation level was assessed by the Academic Motivation Scale created by Vallerand et al. [22]. Satisfaction with academic life measured using the Academic Life Satisfaction Scale (ALSS) developed by Nogueira et al. [23]. Feelings of belonging to the university were assessed by the College Belongingness Questioner (CBQ) developed by Arslan [24].

\section{Data Analysis}

Descriptive statistics were performed using mean (M), standard deviation (SD) for quantitative variables, and percentages for qualitative variables. $T$-test and ANOVA were performed to compare the effect of different variables and to assess the change in various parameters of the study over time or in different groups. Pearson's correlation coefficients, linear, and log-linear regression analysis were performed to evaluate linear relationships and associations of the independent variables with academic motivation. Since a feature of groups 2 and 3 in time 2 was the presence of a blended type of learning, to assess the impact of offline courses, a mediation model was applied to explore the pathway from time of observation via ALSS and CBQ to academic motivation.

Data analysis was conducted using SPSS version 20.0 and Jamovi version 1.2.17. A statistically significant difference was accepted at a $p$-value less than $5 \%$.

\section{Ethics Approval}

The present study was approved by the Local Ethics Committee of NpJSC "Astana Medical University" (extract from protocol No. 6 of April 6, 2020).

\section{Results}

The total number of respondents in time 1 was 273 (203 (74.4\%) were female, and 70 (25.6\%) were male students), with an average age of $17.4(\mathrm{SD}=0.798)$. In time 2,159 students participated (116 (73.0\%) were female, and 43 (27.0\%) were male students), with an average age of 17.8 $(\mathrm{SD}=0.745)$. In time 2, $86(54.1 \%)$ students continued only online training, 33 (20.75\%) students studied offline during the study period, and $40(25.15 \%)$ students by the time of the study had already completed the offline training module and returned to online classes. Thus, in time 2 , students divided into the following three groups: group $1-$ students who continued their studies online, group 2 - students who took offline courses at the time of the study, and group 3 - students who have already completed offline courses and returned to online learning. In the comparison groups, there were no significant differences in gender distribution $(p>0.05)$, and the age of the participants at time 2 was significantly higher than that of time $1(p<0.001)$, but there were no differences in groups $1-3$ of time $2(p>0.05)$.

According to Table 1, internal consistency of all study measures (academic motivation, COV-PDS, COV19QoL, ALSS, CBQ, MHS-SF) was reliable (a Cronbach's alpha $\geq 0.7$ ) [25], Cronbach's alpha coefficient was calculated for total sample in time $1(N=273)$. It should also be noted that only the data of those participants who answered all the questions were included in further analysis. To assess the overall dynamics of individual indicators over time, first, a comparison was made in time 1 and 2, after which to assess these indicators for various forms of education, comparisons of various groups in time 2 with data from time 1 were made. A comparative analysis of level of the motivation and mental well-being indicators in time 1 and time 2 is shown in Table 1. Comparing the research variables over time, it was determined that the level of academic motivation, satisfaction with academic life, sense of belonging to the university, and mental health of students significantly increased/improved in time 2 compared to time 1 . Whereas the levels of COVID-19 induced psychological destruction and changes in quality of life have not changed over time.

Table 1 The level of academic motivation, quality of life affecting by the COVID-19 and destruction from the COVID-19, academic life satisfaction, college belongingness, and mental health continuum in time $1(N=273)$ and time $2(N=159)$

\begin{tabular}{llc}
\hline Variable (Cronbach's alpha) & Time 1 & Time 2 \\
& $M(\mathrm{SD})$ & $M(\mathrm{SD})$ \\
\hline Academic motivation (0.794) & $29.66(7.33)$ & $31.56(6.57)^{*}$ \\
COV-PDS (0.914) & $40.90(16.21)$ & $42.01(16.56)$ \\
COV19-QoL (0.890) & $2.40(1.18)$ & $2.38(1.11)$ \\
ALSS (0.899) & $31.06(7.04)$ & $32.86(6.00)^{*}$ \\
CBQ (0.848) & $52.3(11.12)$ & $55.1(10.24)^{*}$ \\
MHC-SF (0.885) & $47.0(16.18)$ & $50.8(14.03)^{*}$ \\
\hline
\end{tabular}

COV-PDS COVID-19 Psychological Destruction Scale, COV19-QoL Quality of Life affecting by the COVID-19 pandemic, ALSS Academic Life Satisfaction Scale, $C B Q$ College Belongingness Questioner, $M H C$-SF Mental Health Continuum-Short Form ${ }^{*} p<0.05$ 
Table 2 The level of academic motivation, quality of life affected by the COVID-19 and destruction from the COVID-19, Academic Life Satisfaction and College Belongingness in time 2 (group $1-n=86$, group $2-n=33$, group $3-n=40$ )

\begin{tabular}{llll}
\hline Variance & $\begin{array}{l}\text { Group 1 } \\
\text { M (SD) }\end{array}$ & $\begin{array}{l}\text { Group 2 } \\
\text { M (SD) }\end{array}$ & $\begin{array}{l}\text { Group 3 } \\
\text { M (SD) }\end{array}$ \\
\hline Academic motivation & $30.60(6.86)$ & $31.96(7.15)$ & $33.26(5.06)^{*}$ \\
COV-PDS & $42.41(16.36)$ & $41.03(18.37)$ & $41.95(15.81)$ \\
COV19-QoL & $2.43(1.02)$ & $2.43(1.23)$ & $2.22(1.19)$ \\
ALSS & $32.35(5.99)$ & $32.42(5.99)$ & $34.33(5.91)^{*}$ \\
CBQ & $53.5(10.34)$ & $56.2(10.40)$ & $57.5(9.48)^{*}$ \\
MHC-SF & $49.8(12.8)$ & $49.8(16.5)$ & $53.7(14.3)$ \\
\hline
\end{tabular}

COV-PDS COVID-19 Psychological Destruction Scale, COV19-QoL Quality of Life affecting by the COVID-19 pandemic, ALSS Academic Life Satisfaction Scale, $C B Q$ College Belongingness Questioner, $M H C$-SF Mental Health Continuum-Short Form

${ }^{*} p<0.05$ in comparison with time 1

Table 2 presents the results of multiple comparisons using the ANOVA with Tukey post hoc test between the three groups in time 2 with the results from the time 1 . Tukey post hoc test showed significant differences $(p<0.05)$ only in comparison of group 3 and time 1 in the level of academic motivation, ALSS, and CBQ. Thus, only those students who completed offline courses in time 2 (group 3 ) had a significant increase in academic motivation, satisfaction with academic life, and college belongingness compare to initial level in time 1.

Table 3 displays the correlations between the study variables. As expected, positive significant correlations were found between academic motivation and college belongingness, academic life satisfaction, and well-being. Additionally, COVID-19 psychological destruction and quality of life affecting by the COVID-19 were negatively correlated with academic motivation, college belongingness, academic life satisfaction, and well-being. The data in Table 3 show that all the selected study variables are significantly related. However, correlation analysis was carried out for all data in time 1 and 2 for a general understanding of whether the individual indicators are related to each other, and further regression analysis was used to more accurately determine the relationship between individual variables with academic motivation in different study periods and conditions.

Log-linear regression analysis revealed that time of investigation (time 2 vs time 1) was a predictor of academic motivation $(\mathrm{AOR}=1.06,95 \%$ CI 1.03-1.10, $p<0.001)$ with significant overall model test $\left(\chi^{2}=11.8\right.$, $p<0.001)$. However, evaluating the relationship between the three groups in time 2 with time 1, the following results were obtained: group 1 in time 2 vs time 1 (AOR $=1.03$, 95\% CI 0.99-1.08, $p=0.162)$, group 2 in time 2 vs time $1(\mathrm{AOR}=1.08,95 \% \mathrm{CI} 1.01-1.15, p=0.022)$, and group 3 in time 2 vs time $1(\mathrm{AOR}=1.12,95 \%$ CI $1.06-1.19$, $p<0.001)$. Thus, academic motivation was associated with time, and only the conducted and to a greater extent completed offline courses influenced the change in the level of motivation over time.

In linear regression analysis assessing the predicting effect of academic life satisfaction, college belongingness, COVID-19 psychological destruction, and quality of life affecting by the COVID-19 on academic motivation (model fit measure $R^{2}=0.426$ ), only academic life satisfaction $(\beta=0.515)$ and college belongingness $(\beta=0.189)$ showed significant results $(p<0.001)$. Separate calculation of the effect of COV-PDS $(\beta=-0.058)$ and COV19QoL $(\beta=-0.986)$ on academic motivation was significant $(p<0.05)$, but $R^{2}$ was in the range $0.018-0.025$. However, COV19-QoL was a predictor of mental health $(\beta=-0.164$, $p<0,001)$. It follows that while the COVID-19 pandemic was negatively associated with well-being, only academic satisfaction and college belongingness were associated with changes in motivation.

After that, we evaluated the mediating effect of academic life satisfaction and college belongingness on academic motivation (Fig. 2). Indirect effect time $\rightarrow$ college belongingness $\rightarrow$ academic motivation was 0.439 $(\mathrm{SE}=0.18,23.1 \%), p<0.05$. Indirect effect time $\rightarrow$ academic life satisfaction $\rightarrow$ academic motivation was 0.891
Table 3 Correlations of scales (both in time 1 and $2, N=432$ )

\begin{tabular}{lcccccc}
\hline & $(1)$ & $(2)$ & $(3)$ & $(4)$ & $(5)$ & (6) \\
\hline (1) Academic motivation & 1 & & & & & \\
(2) College Belongingness & $0.516^{* *}$ & 1 & & & & \\
(3) Academic Life Satisfaction & $0.612^{* *}$ & $0.583^{* *}$ & 1 & & & \\
(4) COV19-QoL & $-0.160^{* *}$ & $-0.426^{* *}$ & $-0.331^{* *}$ & 1 & & \\
(5) COV-PDS & $-0.133^{*}$ & $-0.372^{* *}$ & $-0.281^{* *}$ & $0.691^{* *}$ & 1 & \\
(6) MHC-SF & $0.531^{* *}$ & $0.509^{* *}$ & $0.626^{* *}$ & $-0.361^{* *}$ & $-0.288^{* *}$ & 1 \\
\hline
\end{tabular}

COV-PDS COVID-19 Psychological Destruction Scale; COV19-QoL Quality of Life affecting by the COVID-19 pandemic; $M H C$-SF Mental Health Continuum-Short Form

${ }^{*} p<0.05 ; * * p<0.001$ 


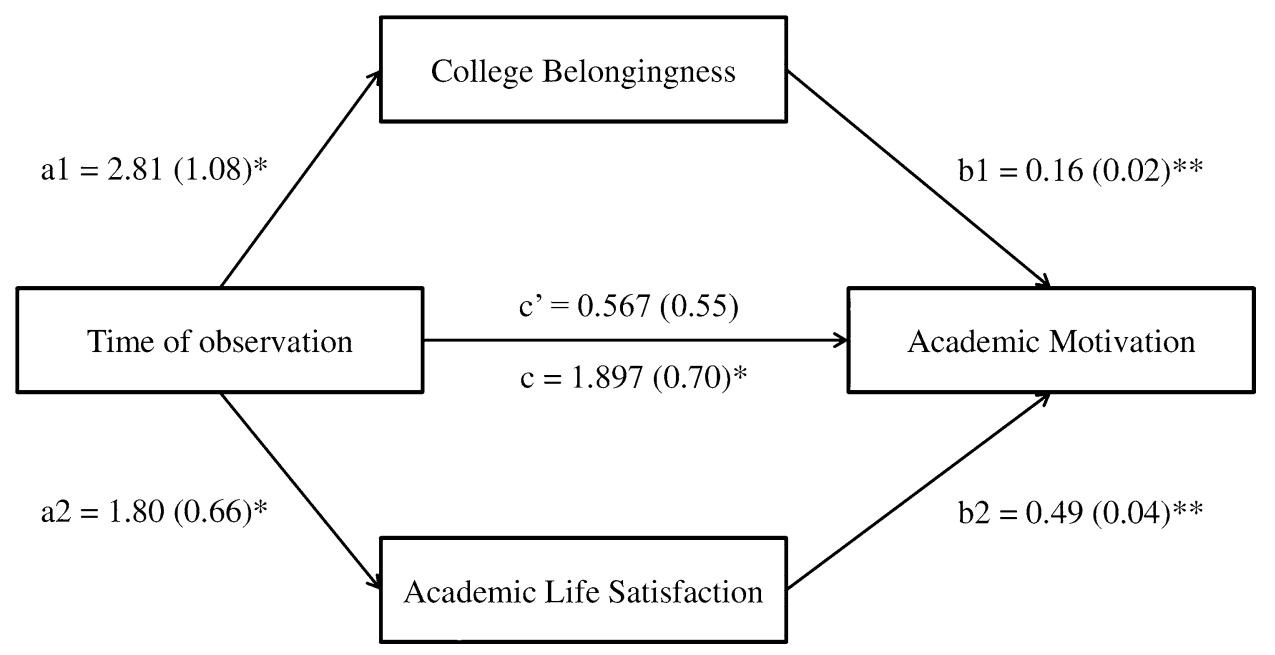

Fig. 2 Mediating effect of academic life satisfaction and college belongingness in the relation between time of observation (time 2 vs time 1) and academic motivation. Note: ${ }^{*} p<0.05 ; * * p<0.001$; all presented effects are unstandardized; a1 the effect of time on academic life satisfaction; b1 the effect of academic life satisfaction on academic motivation; a2 the effect of time on college belongingness; b2 the effect of college belongingness on academic motivation; $c^{\prime}$ is the direct effect of time on academic motivation, and $c$ is the total effect of time on academic motivation

\section{Discussion}

This study aimed to compare the effects of different types of education (online vs blended learning) on the academic motivation of first-year medical students during the COVID19 pandemic, while also considering factors such as academic life satisfaction, college belongingness, and psychological well-being.

In time 2, the level of academic motivation increased in comparison with time 1. Similar results were obtained in South Korea before a pandemic [26]. But the significant relationship between study format and level of motivation was obtained only for group 3 in time 2 compared to time 1 . This suggests that blended learning had a positive effect on the level of student motivation, while learning only online did not lead to a change in the level of motivation. Similar results were found in one quasi-experimental study among nursing students, which showed that the flipped-jigsaw method can improve student academic motivation in distance learning [27]. The points of contact between the students' experience

Table 4 Direct and indirect effects of study condition in group 3 (vs time 1) and academic life satisfaction and college belongingness over academic motivation: coefficients, errors, significance, and effects percentage

\begin{tabular}{llll}
\hline Effects & B & SE & $p$ \\
\hline Total effect of study condition (group 3) on academic motivation & 3.604 & 1.19 & 0.002 \\
Direct effect of study condition (group 3) on academic motivation & 1.178 & 0.93 & 0.209 \\
Indirect effect group 3 $\rightarrow$ college belongingness $\rightarrow$ academic motivation & 0.812 & 0.31 & 0.008 \\
Indirect effect group 3 $\rightarrow$ academic life satisfaction $\rightarrow$ academic motivation & 1.614 & 0.57 & 0.005 \\
\hline
\end{tabular}


in the current study and the teaching carried out in flipped format is the possibility of combining both online and offline classes. Erbil and Kocabaş indicate that the flipped classroom and collaborative teaching methods have resulted in more positive intrinsic motivation through increased levels of competence, autonomy, and belonging among students [28]. In support of this, the present study found that college belongingness was a mediated factor in the relationship between form of education and motivation. However, the question remains why a significant increase in the level of academic motivation was observed only in group 3, and not in group 2 . This can be explained by several possible factors: firstly, students from group 2 completed only $2 / 3$ of the study load of group 3 in an offline format; secondly, it is worth noting that students from group 3 , having returned to the online format, overestimated their learning in full, comparing different forms of education; thirdly, there were many other organizational factors associated with both teachers and the experience of individual students.

COVID-19-related psychological state was assessed using the COV-PDS and COV19-QoL. According to Tables 1 and 2 , average values on these scales did not change in time 2 compared to time 1 . Moreover, mental health continuum increased in time 2 compared to time 1 . This indicates the stability of the mental state of 1-year students over time. These results can be explained by the fact that in this period of time, there was a relatively stable epidemiological situation in terms of the prevalence of COVID-19. At the same time, these indicators were negatively correlated with the level of academic motivation. However, these variables had no effect on changes in the level of academic motivation overtime or had a minor effect.

Correlation analysis showed that the level of motivation was positively associated with the level of satisfaction with academic life and college belongingness. Moreover, the study found that the level of academic life satisfaction and college belongingness increased in time 2 compared to period 1 . This was especially noticeable comparing students who have already taken offline courses with initial levels in time 1. While virtual learning is effective [29], the transition to blended learning has positively impacted academic motivation. This confirms that mentoring can help stimulate student motivation during the COVID-19 pandemic [30], which is more effective in face-to-face contact with the mentor. Moreover, lack of psychological and social support from institutions can hinder learning as a result of reduced motivation during a pandemic $[31,32]$.

Since satisfaction with academic life and college belongingness can be related to the form of education, we decided to evaluate their indirect effect on the level of academic motivation, the mediation model presented in Fig. 2. As hypothesized, satisfaction with academic life and college belongingness mediated the influence of time and study format on academic motivation; however, the direct association between time of observation, study format, and motivation was not statistically significant. This finding might be because of the positive link we found between study format and motivation. Moreover, the mediated role of academic life satisfaction had a relatively greater contribution to motivation than the direct influence of time ( $47 \%$ vs $30 \%)$ and experience in blended learning (44.8\% vs $32.7 \%)$. Satisfaction with academic life assessed by the ALSS has two dimensions: personal (internal) satisfaction, which describes students' skills and competencies, perceptions of academic performance and relationships with colleagues and teachers, and satisfaction with the academic environment (external), which describes the physical and educational environment, interest and commitment to course, extracurricular activities of the institution, and learning conditions [23]. In this study, personal satisfaction showed the greatest and most reliable mediated effect of time on academic motivation. From which it follows that the possibility of live communication in training during the offline learning and not the physical presence at the university itself had a positive effect on students' motivation. Earlier, Arslan et al. found a mediating role of college belongingness between the coronavirus anxiety and psychological adjustment in college students [33]. Thus, providing favorable conditions for teaching medical students can become one of the ways to maintain and increase student motivation. And blended learning allows finding a compromise between an effective learning and a controlled epidemiological environment during a pandemic. Also, the importance of hybrid forms of education was emphasized in the organization of agricultural education, which also provides for the training of a large number of practical skills [34].

Some limitations need to be considered in this study. First, this study is cross-sectional; further cohort studies are needed to determine more accurate results. Moreover, the number of respondents was limited. There may be more than two mediators in the relationship between study format during the COVID-19 pandemic and academic motivation. Finally, further epidemiological studies are needed to assess the safety of blended learning.

\section{Conclusion}

We found that the mental state of the 1-year students was stable overtime during the COVID-19 pandemic. The level of academic motivation was higher in the second semester; this was especially noticeable among students who underwent blended learning. The mediating role of satisfaction with academic life and college belongingness in the relationship between the learning format and academic motivation was significant. Thus, the transition from online education 
to a blended type of education during a pandemic was more favorable for students in terms of their motivation to study. However, further epidemiological studies are needed to assess the safety of blended learning. Further exploration of the role of different forms of study on student learning outcomes, taking into account more possible related factors, will enable educational policy-makers and university administrators to design effective curricula in global health crises such as the COVID-19 pandemic.

Acknowledgements The author thanks the dean's office of the Faculty of Medicine at the Astana Medical University for their support in this study.

Author Contribution Conceptualization: Aidos K. Bolatov and Anar M. Gabbasova; methodology: Raushan K. Baikanova and Bahyt B. Igenbayeva; formal analysis: Aidos K. Bolatov; investigation: Anar M. Gabbasova, Bahyt B. Igenbayeva, Raushan K. Baikanova; writing — original draft preparation: Aidos K. Bolatov; writing — review and editing: Dainius Pavalkis; Supervision: Dainius Pavalkis.

Availability of Data and Material All data available by request to corresponding author.

\section{Declarations}

Ethics Approval The present study was approved by the Local Ethics Committee of NpJSC "Astana Medical University" (extract from protocol No. 6 of April 6, 2020).

Consent to Participate Not applicable

Consent for Publication Not applicable.

Conflict of Interest The authors declare no competing interests.

\section{References}

1. Goel S, Angeli F, Dhirar N, Singla N, Ruwaard D. What motivates medical students to select medical studies: a systematic literature review. BMC Med Educ. 2018;18(1):16. https://doi.org/10.1186/ s12909-018-1123-4.

2. Gąsiorowski J, Rudowicz E, Safranow K. Motivation towards medical career choice and future career plans of Polish medical students. Adv Health Sci Educ Theory Pract. 2015;20(3):709-25. https://doi.org/10.1007/s10459-014-9560-2.

3. Narayanasamy M, Ruban A, Sankaran PS. Factors influencing to study medicine: a survey of first-year medical students from India. Korean J Med Educ. 2019;31(1):61-71. https://doi.org/10.3946/ kjme.2019.119.

4. Shreffler J, Petrey J, Huecker M. The impact of COVID-19 on healthcare worker wellness: a scoping review. West J Emerg Med. 2020;21(5):1059-66. https://doi.org/10.5811/westjem.2020.7.48684.

5. Stetson GV, Kryzhanovskaya IV, Lomen-Hoerth C, Hauer KE. Professional identity formation in disorienting times. Med Educ. 2020;54(8):765-6. https://doi.org/10.1111/medu.14202.

6. Slivkoff MD, Johnson C, Tackett S. First-year medical student experiences adjusting to the immediate aftermath of COVID-19. Med Sci Educ. 2021. https://doi.org/10.1007/s40670-021-01213-1.
7. Wasityastuti W, Susani YP, Prabandari YS, Rahayu GR. Correlation between academic motivation and professional identity in medical students in the Faculty of Medicine of the Universitas Gadjah Mada Indonesia. Educacion Medica. 2018;19(1):23-9. https://doi.org/10.1016/j.edumed.2016.12.010.

8. Findyartini A, Anggraeni D, Husin JM, Greviana N. Exploring medical students' professional identity formation through written reflections during the COVID-19 pandemic. J Public Health Res. 2020;9(Suppl 1):1918. https://doi.org/10.4081/jphr.2020.1918.

9. Chandratre S. Medical students and COVID-19: challenges and supportive strategies. J Med Educ Curric Dev. 2020. https://doi. org/10.1177/2382120520935059.

10. Pelaccia T, Viau R. Motivation in medical education. Med Teach. 2017;39(2):136-40. https://doi.org/10.1080/0142159X.2016.1248924.

11. Orsini C, Binnie VI, Wilson SL. Determinants and outcomes of motivation in health professions education: a systematic review based on self-determination theory. J Educ Eval Health Prof. 2016;13:19. https://doi.org/10.3352/jeehp.2016.13.19.

12. Deshetler L., Gangadhar M., Battepati D., Koffman E., Mukherjee R. K., \& Menon B. Learning on Lockdown: A Study on Medical Student Wellness, Coping Mechanisms and Motivation during the COVID-19 Pandemic. MedEdPublish, 2021;10(1). https://doi.org/ 10.15694/mep.2021.000050.1.

13. Lee I, Koh H, Lai SH, Hwang NC. Academic coaching of medical students during the COVID-19 pandemic. Med Educ. 2020;54(12):1184-5. https://doi.org/10.1111/medu.14272.

14. Rahm A-K, Töllner M, Hubert MO, Klein K, Wehling C, Sauer $\mathrm{T}$, et al. Effects of realistic e-learning cases on students' learning motivation during COVID-19. PLoS One. 2021;16(4):e0249425. https://doi.org/10.1371/journal.pone.0249425.

15. Sahu P. Closure of universities due to coronavirus disease 2019 (COVID-19): impact on Education and Mental Health of Students and Academic Staff. Cureus. 2020;12(4):e7541. https://doi.org/10. 7759/cureus.7541.

16. Saladino V, Algeri D, Auriemma V. The psychological and social impact of covid-19: new perspectives of well-being. Front Psychol. 2020;11: 577684. https://doi.org/10.3389/fpsyg.2020. 577684.

17. González Olivares ÁL, Navarro Ó, Sánchez-Verdejo FJ, Muelas Á. Psychological well-being and intrinsic motivation: relationship in students who begin university studies at the School of Education in Ciudad Real. Front Psychol. 2020;11:2054. https://doi.org/10. 3389/fpsyg.2020.02054.

18. Dirzyte A, Vijaikis A, Perminas A, Rimasiute-Knabikiene R. Associations between depression, anxiety, fatigue, and learning motivating factors in e-learning-based computer programming education. Int J Environ Res Public Health. 2021;18(17):9158. https://doi.org/10.3390/ijerph18179158.

19. Repišti S, Jovanović N, Kuzman MR, Medved S, Jerotić S, Ribić E, Majstorović T, Simoska SM, Novotni L, Milutinović M, Stoilkovska BB, Radojičić T, Ristić I, Zebić M, Pemovska T, Russo M. How to measure the impact of the COVID-19 pandemic on quality of life: COV19-QoL - the development, reliability and validity of a new scale. Global Psychiatry. 2020: 000010247820200016. https://doi. org/10.2478/gp-2020-0016.

20. Akan Y. Development of the "COVID-19 psychological destruction scale": a validity and reliability study. In Review, 2020 [cited 23 August 2020]. https://doi.org/10.21203/rs.3.rs-46890/v1.

21. Keyes CL, Wissing M, Potgieter JP, Temane M, Kruger A, Van Rooy S. Evaluation of the mental health continuum-short form (MHC-SF) in Setswana-speaking south Africans. Clin Psychol Psychother. 2008;15:181-92.

22 Vallerand RJ, Pelletier LG, Blais MR, Briere NM, Senecal C, Vallieres EF. The Academic Motivation Scale: a measure of intrinsic, extrinsic, and amotivation in education. Educ Psychol Meas. 1992;52(4):100317. https://doi.org/10.1177/0013164492052004025. 
23. Nogueira MJ, et al. Development and Psychometric Study of the Academic Life Satisfaction Scale (ALSS) in a higher education students sample. Nurs Health Care Int J. 2019;3(2):000183.

24. Arslan G. Loneliness, college belongingness, subjective vitality, and psychological adjustment during coronavirus pandemic: Development of the College Belongingness Questionnaire. Journal of Positive School Psychology. 2021;5(1), 17-31. https://doi.org/ 10.47602/jpsp.v5i1.240.

25. Taber KS. The use of Cronbach's alpha when developing and reporting research instruments in science education. Res Sci Educ. 2018;48(6):1273-96. https://doi.org/10.1007/s11165-016-9602-2.

26. Kim KJ, Jang HW. Changes in medical students' motivation and self-regulated learning: a preliminary study. Int J Med Educ. 2015;6:213-5. https://doi.org/10.5116/ijme.565e.0f87.

27. Haftador AM, Shirazi F, Mohebbi Z. Online class or flipped-jigsaw learning? Which one promotes academic motivation during the COVID-19 pandemic? BMC Med Educ. 2021;21(1). https:// doi.org/10.1186/s12909-021-02929-9.

28. Erbil DG, Kocabas A. Flipping the 4th grade social studies course in a cooperative way: effects on academic achievement and motivation. Stud Educ Eval. 2020;66:100878. https://doi.org/10. 1016/j.stueduc.2020.100878.

29. Wilcha RJ. Effectiveness of virtual medical teaching during the COVID-19 crisis: systematic review. JMIR Med Educ. 2020;6(2):e20963. https://doi.org/10.2196/20963.
30. Hamad SMS, Iqbal S, Alothri AM, Alghamadi MAA, Elhelow MKKA. "To teach is to learn twice" added value of peer learning among medical students during COVID-19 Pandemic. MedEdPublish. 2020;9(1). https://doi.org/10.15694/mep.2020.000127.1.

31. Kaup S, Jain R, Shivalli S, Pandey S, Kaup S. Sustaining academics during COVID-19 pandemic: the role of online teachinglearning. Indian J Ophthalmol. 2020;68(6):1220-1. https://doi. org/10.4103/ijo.IJO_1241_20.

32. Longhurst GJ, Stone DM, Dulohery K, Scully D, Campbell T, Smith CF. Strength, weakness, opportunity, threat (SWOT) analysis of the adaptations to anatomical education in the United Kingdom and Republic of Ireland in response to the Covid-19 pandemic. Anat Sci Educ. 2020;13(3):301-11. https://doi.org/10.1002/ase.1967.

33. Arslan G, Yıldırım M, Zangeneh M. Coronavirus anxiety and psychological adjustment in college students: exploring the role of college belongingness and social media addiction. Int J Ment Heal Addict. 2021: 1-14. https://doi.org/10.1007/s11469-020-00460-4.

34. Muthuprasad T, Aiswarya S, Aditya KS, Jha GK. Students' perception and preference for online education in India during COVID -19 pandemic. Soc Sci Humanit Open. 2021;3(1): 100101. https://doi.org/10.1016/j.ssaho.2020.100101.

Publisher's Note Springer Nature remains neutral with regard to jurisdictional claims in published maps and institutional affiliations. 